\title{
Treatment of Hepatitis Delta
}

\author{
Heiner Wedemeyer, Svenja Hardtke, and Michael P. Manns
}

Hepatitis Delta, which is caused by infection of hepatitis B surface antigen (HBsAg)-positive individuals with the hepatitis D virus (HDV), is considered the most severe form of chronic viral hepatitis. HDV uses HBsAg as its envelope, and hepatitis Delta can therefore only occur in patients who have hepatitis B, either as simultaneous coinfection or superinfection. HDV infection has been associated with more rapid progression of liver disease as well as increased frequencies of hepatocellular carcinoma. ${ }^{1} \mathrm{HDV}$ is highly prevalent in some eastern European countries such as Romania and Turkey. In addition, HDV infection is frequent in central Asia and Pakistan. Other regions where hepatitis Delta represents a major health problem include the western Amazonian area (Brazil and Peru), sub-Saharan Africa, and certain Pacific islands. ${ }^{2}$ HDV infection can also be found in the United States, where up to $50 \%$ of HBsAg-positive injection drug users are antiHDV-positive ${ }^{3}$ (Fig. 1).

\section{Diagnosis}

Diagnosis of hepatitis Delta is based on the detection of anti-HDV antibodies in patients who are HBsAg-positive (Table 1). The vast majority of hepatitis Delta patients are negative for hepatitis $\mathrm{B} e$ antigen (HBeAg) and are anti-HBe-positive, which can be explained in part by suppression of HBV replication by hepatitis Delta antigens. However, this suppression does not lead to deletion of intrahepatic HBV covalently closed circular DNA; therefore, HBV DNA values are frequently very low in hepatitis Delta despite persistence of high HBsAg levels. More than two thirds of anti-HDV/immunoglobulin G-positive patients have active HDV infection with detectable HDV RNA. At least eight different HDV genotypes have been described, with HDV genotype 1 being the most prevalent in North America and Europe. ${ }^{2}$ Because HDV RNA assays lack standardization, testing for anti-HDV/immunoglobulin $\mathrm{M}$ may be useful in HDV RNA-negative/HBsAg-positive individuals who still have unexplained elevated liver enzymes. Anti-HDV/immunoglobulin $\mathrm{M}$ levels are associated with activity of liver disease and may therefore yield additional clinical information. ${ }^{4}$

\section{Treatment}

The primary goal of treatment of hepatitis Delta is to suppress HDV RNA replication, which is usually associated with normalization of liver enzymes and histological improvement of liver disease. Ideally, antiviral therapy induces serological cure from hepatitis B defined by HBsAg loss and development of anti-HBs antibodies, simultaneously leading to recovery from HDV infection.

HDV does not encode for any viral enzyme but uses host polymerases for replication. It is therefore not unexpected that nucleoside and nucleotide analogs used for the treatment of hepatitis B and C are ineffective to reduce HDV replication. ${ }^{5,6}$ Reduction or even suppression of HDV RNA levels can currently be achieved by administration of type 1 interferons only. Different types of recombinant or natural interferon- $\alpha$ (IFN $\alpha$ ) were used to treat hepatitis Delta in the late 1980s and 1990s, leading to normalization of alanine aminotransferase levels in 20\%-50\% of patients (although this normalization was frequently only transient). Higher doses of IFN $\alpha$ and longer treatment durations were considered to be beneficial and have been associated with improved clinical long-term outcome. ${ }^{7}$ Pegylated IFN $\alpha$ (PEGIFN $\alpha$ ) therapy is associated with HDV RNA negativity in 25\%$40 \%$ of cases after 1 year. ${ }^{6,8}$ There is preliminary evidence for late HDV RNA relapses even beyond 24 weeks after the end of PEG-IFN $\alpha$ treatment and thus HDV RNA levels should be monitored regularly even in patients who responded to therapy (Fig. 2). Combination therapies of PEG-IFN $\alpha$ with ribavirin or adefovir did not increase virological response rates concerning HDV RNA. ${ }^{6,8}$ Trials investigating longer therapies with PEGIFN $\alpha$ and combinations with tenofovir are currently ongoing.

HBsAg loss may be achieved in single hepatitis Delta patients using prolonged interferon therapy. ${ }^{9}$ Monitoring of

Abbreviations: HBeAg, hepatitis B e antigen; HBsAg, hepatitis B surface antigen; HDV, hepatitis D virus; IFN $\alpha$, interferon- $\alpha$; PEG-IFN, pegylated interferon- $\alpha$. From the Department of Gastroenterology, Hepatology, and Endocrinology, Hannover Medical School, Hannover, Germany.

Potential conflict of interest: Nothing to report.

View this article online at wileyonlinelibrary.com

(C) 2013 by the American Association for the Study of Liver Diseases

doi: $10.1002 /$ cld.254 


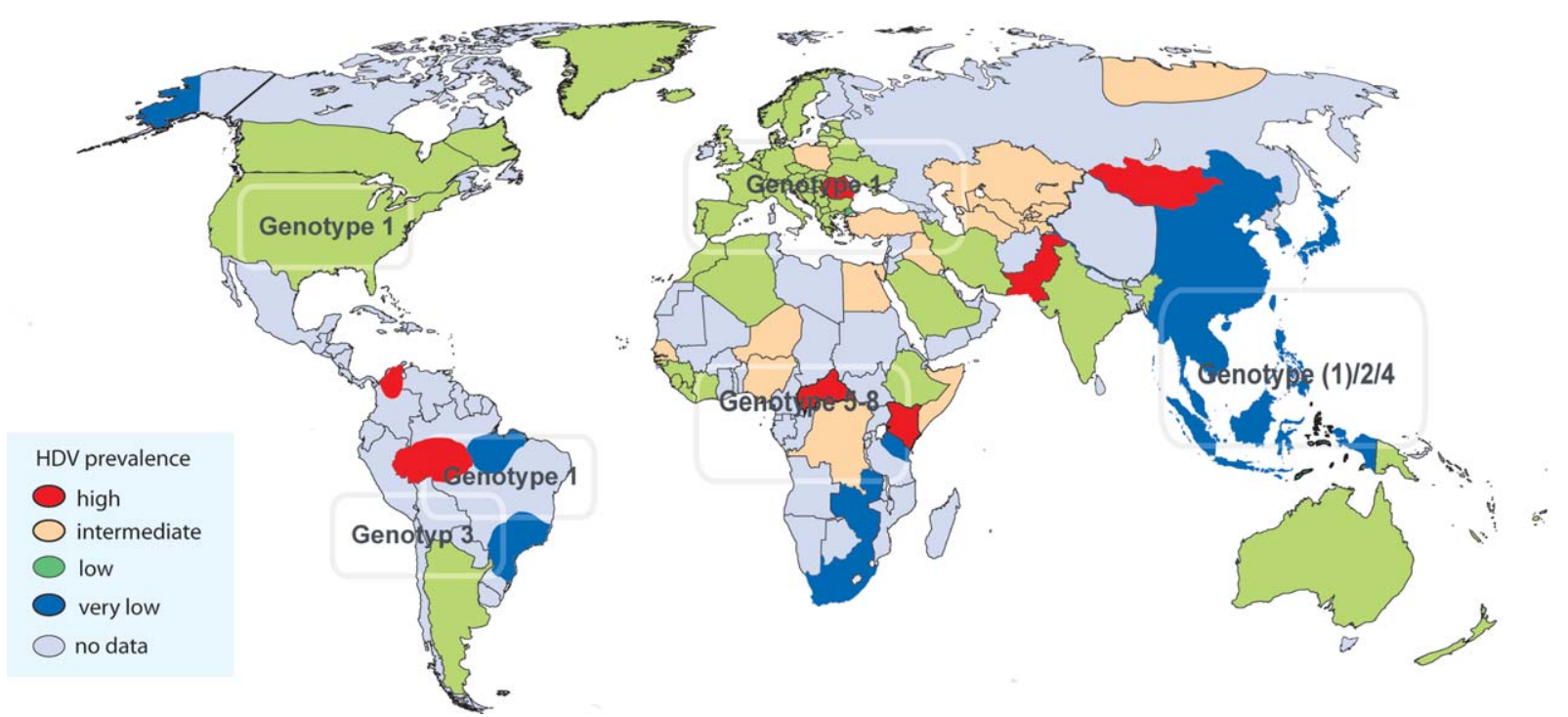

FIGURE 1 HDV prevalence and genotype.

quantitative HBsAg levels is useful for individualization of patient management to identify subjects who benefit from PEG-IFN $\alpha$ maintenance treatment. PEG-IFN $\alpha$ plus adefovir was superior to reduce HBsAg levels in hepatitis Delta patients compared with either drug alone, ${ }^{8}$ but the efficacy of other combinations to lower or even clear HBsAg still need to be explored in HDV-infected individuals.

\section{Alternative Options}

Long-term monotherapy with nucleoside or nucleotide analogs could be considered in hepatitis Delta patients with active HBV replication and positive HBV DNA levels. Because HBV replication also contributes to liver disease in hepatitis Delta, the underlying HBV infection should be treated according to HBV guidelines. However, only a minority of patients on nucleoside or nucleotide monotherapy show declines of HBsAg levels, and these treatments are not recommended for hepatitis Delta patients who have very low or negative HBV DNA levels.

Liver transplantation remains the only treatment option for many hepatitis Delta patients who have end-stage liver disease.
Hepatitis Delta patients have a lower risk for HBV reinfection after transplantation than monoinfected patients. If prophylaxis by passive immunization with anti-HBs antibodies and administration of HBV polymerase inhibitors is applied, HBV/HDV reinfection can be prevented in all individuals, leading to an excellent long-term outcome after transplantation. HDV RNA levels rapidly decline during the first days after transplantation, but HDAg may persist in the transplanted liver for several years. ${ }^{1}$ Long-term prophylaxis to prevent HBV reinfection should be recommended in hepatitis Delta transplantation patients, because reinfection may lead to HDV reactivation, the treatment options for which are very limited.

\section{Future Therapies}

Possible future treatment options include novel therapies leading to HBsAg clearance. In addition, posttranslational modification steps of hepatitis Delta antigens (e.g., methylation, acetylation, phosphorylation, and isoprenylation) are potential therapeutic targets. Prenylation of the hepatitis D large antigen is essential for virion assembly, and inhibition of prenylation has shown potent antiviral effects in an

TABLE 1 Diagnostic Tests for Hepatitis Delta Infection

\begin{tabular}{|c|c|c|}
\hline Indication & Test & Remarks \\
\hline Previous/ongoing contact with HDV & Anti-HDV/immunoglobulin G & Standard screening test for all HBsAg-positive patients \\
\hline $\begin{array}{l}\text { Acute or chronic HDV infection with } \\
\text { disease activity }\end{array}$ & Anti-HDV/immunoglobulin M & $\begin{array}{l}\text { Positive in acute hepatitis delta and chronic patients with disease } \\
\text { activity, but not flares; available tests are not standardized }\end{array}$ \\
\hline Presence of HDV RNA in blood & HDV RNA--qualitative & $\begin{array}{l}\text { Standard to determine HDV infection; may be false negative if test is } \\
\text { not optimized for all genotypes }\end{array}$ \\
\hline HDV replication and active infection & HDV RNA--quantitative & $\begin{array}{l}\text { Useful to monitor treatment response; available tests are not } \\
\text { standardized }\end{array}$ \\
\hline HDV genotype & HDV genotyping & Different genotypes may be associated with distinct clinical courses \\
\hline Levels of HBsAg in the blood & HBsAg--quantitative & $\begin{array}{l}\text { Associated with HDV RNA levels; loss of HBsAg implies HDV } \\
\text { eradication; useful to monitor treatment response }\end{array}$ \\
\hline $\begin{array}{l}\text { Presence of } \mathrm{HBeAg} \text { or seroconversion to } \\
\text { anti-HBe antibodies }\end{array}$ & $\mathrm{HBeAg} / \mathrm{anti}-\mathrm{HBe}$ & $\begin{array}{l}\text { Only a minority of HDV patients have HBeAg; useful to decide HBV } \\
\text { treatment }\end{array}$ \\
\hline
\end{tabular}




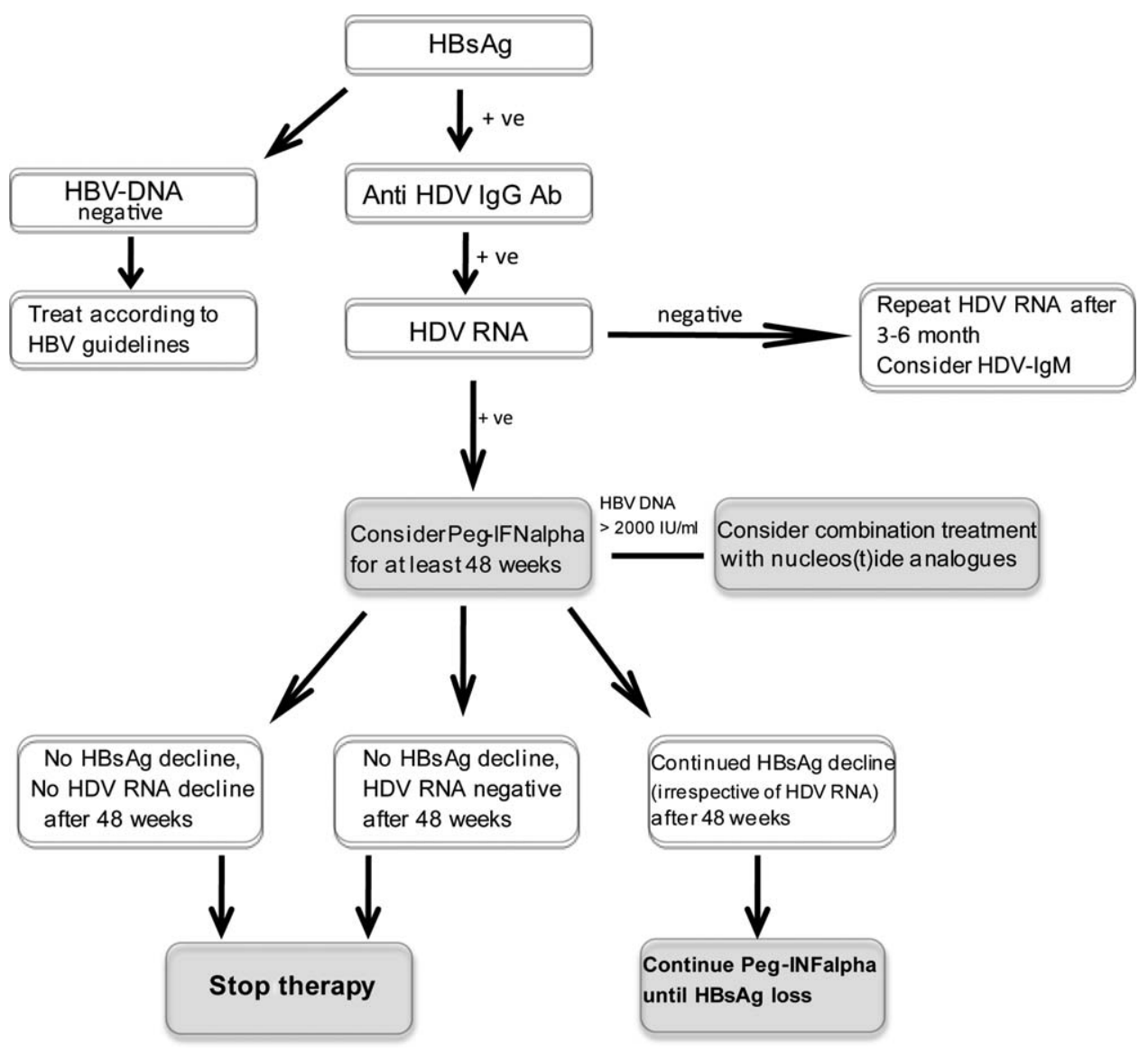

FIGURE 2 Diagnosis and treatment of hepatitis Delta.

animal model of hepatitis Delta. ${ }^{10}$ Clinical trials are currently investigating different prenylation inhibitors to treat HDV infection in patients, and the first results are expected to become available within the next 12 months.

\section{Conclusion}

Treatment of hepatitis Delta remains a major challenge, and the options to induce a cure of HDV infection are limited. Therapy should be individualized based on the stage

\section{References}

1. Wedemeyer H, Manns MP. Epidemiology, pathogenesis and management of hepatitis D: update and challenges ahead. Nat Rev Gastroenterol Hepatol 2010;7:31-40.

2. Hughes SA, Wedemeyer H, Harrison PM. Hepatitis delta virus. Lancet 2011; 378:73-85.

3. Kucirka LM, Farzadegan H, Feld JJ, Mehta SH, Winters M, Glenn JS, et al. Prevalence, correlates, and viral dynamics of hepatitis Delta among injection drug users. J Infect Dis 2010;202:845-852.

4. Mederacke I, Yurdaydin C, Dalekos GN, Bremer B, Erhardt A, Cakaloglu Y, et al. Anti-HDV immunoglobulin M testing in hepatitis delta revisited: correlations with disease activity and response to pegylated interferon-alpha2a treatment. Antivir Ther 2012;17:305-312

5. Niro GA, Rosina F, Rizzetto M. Treatment of hepatitis D. J Viral Hepat 2005; $12: 2-9$. of liver disease, the status of both HBV and HDV replication, and response kinetics during therapy, in particular concerning quantitative HBsAg levels. Prenylation inhibitors currently represent the most promising treatment option.

\section{CORRESPONDENCE}

Heiner Wedemeyer, Department of Gastroenterology, Hepatology, and Endocrinology, Hannover Medical School, Carl-Neuberg-Str. 1, 30625 Hannover, Germany. E-mail: wedemeyer.heiner@mh-hannover.de.

6. Heidrich B, Manns MP, Wedemeyer H. Treatment options for hepatitis delta virus infection. Curr Infect Dis Rep 2013;15:31-38.

7. Farci P, Roskams T, Chessa L, Peddis G, Mazzoleni AP, Scioscia R, et al. Long-term benefit of interferon alpha therapy of chronic hepatitis D: regression of advanced hepatic fibrosis. Gastroenterology 2004;126:17401749 .

8. Wedemeyer H, Yurdaydin C, Dalekos GN, Erhardt A, Cakaloglu Y, Degertekin $\mathrm{H}$, et al. Peginterferon plus adefovir versus either drug alone for hepatitis delta. N Engl J Med 2011;364:322-331.

9. Lau DT, Doo E, Park Y, Kleiner DE, Schmid P, Kuhns MC, Hoofnagle JH. Lamivudine for chronic delta hepatitis. Hepatology 1999;30:546-549.

10. Bordier BB, Ohkanda J, Liu P, Lee SY, Salazar FH, Marion PL, et al. In vivo antiviral efficacy of prenylation inhibitors against hepatitis delta virus. J Clin Invest 2003;112:407-414. 